\title{
Melting Temperature of Thermally Reversible Gel. V. Heat of Fusion of Cellulose Triacetate and the Melting of Cellulose Diacetate-Benzyl Alcohol Gel
}

\author{
Akira TAKAHASHI, Toyoharu KAWAHARADA, and Tadaya KATO \\ The Chemistry Department of Industry and Resources, Faculty of Engineering, \\ Mie University, Tsu, Mie 514, Japan.
}

(Received April 6, 1979)

\begin{abstract}
The heat of fusion of cellulose triacetate was determined from the melting point depression to be $2360 \mathrm{cal} \mathrm{mol}^{-1}\left(9.87 \mathrm{~kJ} \mathrm{~mol}^{-1}\right)$. The melting temperatures of thermally reversible gels of cellulose acetate in benzyl alcohol were measured over a range of polymer concentrations. The reciprocal of the gel melting temperature $v s$. $\ln v_{2} x_{w}$ plot is linear, where $v_{2}$ is the polymer volume fraction in the gel and $x_{w}$ is the weight-average degree of polymerization. The plot was analysed according to the thermodynamic theory of the melting of a gel and the crosslinking loci in the gel were inferred to be crystallites consist of triacetyl glucose units.
\end{abstract}

KEY WORDS Cellulose Triacetate / Cellulose Diacetate / Acetyl Cellulose / Heat of Fusion / Gel / Sol-Gel Transition /

The sol-gel transition of secondary cellulose acetate has been receiving attention. The supramolecular structure of cellulose acetate gel is important for understanding the properties of cellulose acetate films prepared by the solvent cast and evaporation method, since the films are technically important for reverse osmosis. The thermally reversible gel formation of cellulose acetate in benzyl alcohol has been studied by several authors. ${ }^{1,2}$ Recently, Goebel and Berry ${ }^{3}$ investigated the supramolecular structure of the gel by light scattering and elasticity measurements. They concluded that the nonrandom character of the cross linking loci in the gel causes the smallangle light scattering. Furthermore, they estimated that the equivalent diameter $D$ of the cross linking loci was $147 \AA$ from low-angle X-ray scattering and the formation of the cross linking loci was attributed to the three dimensional nucleation process. However, the length of the crystallite could not be estimated.

In preceding papers of this series, one (AT) of the authors developed a thermodynamic theory for the melting of thermally reversible gels, assuming that cross linking locus is the crystallite of length $\zeta$ units. $^{4}$ Despite that the melting point of gel is not the thermodynamic singularity, ${ }^{4}$ according to this theory, the melting temperature of the gel $\left(T_{\mathrm{m}}^{\mathrm{g}}\right)$ is given by

$$
\begin{aligned}
\frac{1}{T_{\mathrm{m}}^{\mathrm{g}}}= & \frac{\zeta}{\left(\zeta \Delta h_{\mathrm{u}}+\zeta B^{\prime} V_{\mathrm{A}}-2 \sigma_{\mathrm{ec}}\right)}\left(\frac{\Delta h_{\mathrm{u}}}{T_{\mathrm{m}}^{0}}+\frac{R V_{\mathrm{A}}}{V_{1}}-R \ln X_{\mathrm{A}}\right) \\
& -\frac{R}{\left(\zeta \Delta h_{\mathrm{u}}+\zeta B^{\prime} V_{\mathrm{A}}-2 \sigma_{\mathrm{ec}}\right)} \ln v_{2} x_{w}
\end{aligned}
$$

In this equation, $\Delta h_{\mathrm{u}}$ is the heat of fusion per crystalline monomer unit, $T_{\mathrm{m}}{ }^{0}$ is the melting temperature of pure polymer, $\sigma_{\mathrm{ec}}$ is the end interfacial free energy of the crystallite, $B^{\prime}$ is the cohesive energy density of interaction between the crystalline unit $A$ and the solvent medium which consists of a diluent and noncrystalline units, $V_{\mathrm{A}}, V_{1}$ are the molar volumes of the crystalline unit and the solvent, respectively, $v_{2}$ is the volume fraction of the polymer in the gel, $X_{\mathrm{A}}$ is the mole fraction of crystalline unit and $x_{w}$ is the weight-average degree of polymerization. Equation 1 has been applied to evaluate the crystalline length $\zeta$ and interfacial free energy $\sigma_{\mathrm{ec}}$ for many thermally reversible gels and $\zeta$ thus evaluated compared favorably with $\zeta$ values estimated by other methods such as spectroscopy, elasticity and swelling of gels. ${ }^{5,6,7}$ 


\section{A. Takahashi, T. Kawaharada, and T. Kato}

The purpose of the present article is to evaluate $\zeta$ of the crystalline cross links in the cellulose acetate-benzyl alcohol gel and compare these values with the X-ray diffraction of gels. Not only through the study of melting of the gels, the $\Delta h_{\mathrm{u}}$ is also evaluated from the melting point depression of a cellulose triacetate-diluent system, since the $\Delta h_{\mathrm{u}}$ of cellulose triacetate has not yet been reported as far as we know.

\section{EXPERIMENTAL}

\section{Materials}

Daicel Cellulose Triacetate (hereafter abbreviated as CTA) was used. The degree of substitution was found to be 2.90. Daicel cellulose diacetate (hereafter abbreviated as CDA) was found to have a degree of substitution 2.55. The CDA was dissolved in acetone, fractionated at $296 \mathrm{~K}$ by adding ethanol as precipitant and ten fractions were obtained. Their intrinsic viscosities were determined in tetrahydrofuran and the molecular weight was determined by the viscosity equation

$$
[\eta]=7.46 \times 10^{-4} M_{w}^{0.672}
$$

which was calculated by using Tanner and Berry's data. $^{8}$ The acetyl content of each fraction was determined by the alkaline hydrolysis method. The characteristics of the samples used in this study are summarized in Table I.

\section{Thermodynamic Property}

The heat of fusion of CTA was estimated from the melting point depression of the CTA-diluent system. Dibutyl phthalate was selected as a diluent and the

Table I. Characteristics of cellulose diacetate fractions

\begin{tabular}{ccccc}
\hline & & {$[\eta]$} & & \\
Sample No. & \multicolumn{1}{c}{$M_{w}$} \\
\cline { 2 - 3 }$\times 10^{-5}$ & $\mathrm{DP}^{\mathrm{a}}$ & $\mathrm{DS}^{\mathrm{b}}$ \\
\hline 1 & 4.04 & 3.59 & 1391 & 2.29 \\
2 & 3.59 & $3.01_{5}$ & 1165 & $2.29_{8}$ \\
3 & 2.94 & 2.24 & 865 & $2.30_{3}$ \\
4 & 2.20 & $1.45_{5}$ & 559 & $2.33_{5}$ \\
5 & 1.80 & $1.07_{9}$ & 416 & 2.31 \\
6 & 1.04 & $0.47_{7}$ & 184 & 2.30 \\
\hline
\end{tabular}

a Degree of polymerization.

b Degree of substitution. melting points of the CTA-diluent mixtures were determined using a Perkin-Elmer differential scanning calorimeter Model IB. The weighted amount of CTA samples and the diluent were mixed by stirring in test tubes at $573 \mathrm{~K}$, then slowly cooled to 293 $\mathrm{K}$, and kept at this temperature for $24 \mathrm{~h}$ to crystallize the mixtures.

Melting Temperature and X-ray Diffraction of Gels Gels of CDA-benzyl alcohol systems were prepared at $277 \mathrm{~K}$ for 43 hours in U-shaped tubes as decribed previously. ${ }^{4}$

The U-tubes were then heated at the rate $273.5 \mathrm{~K} \mathrm{~min}^{-1}$ and the temperature at which a pressure head caused flow through a fine cappillary was employed as the melting temperature of the gels $\left(T_{\mathrm{m}}^{\mathrm{g}}\right)$

The X-ray diffraction patterns of CTA film cast from a methylene chloride-ethanol mixture $(9: 1)$, a CDA film cast from acetone and CDA gels $(10 \mathrm{wt} \%)$ were obtained by a Rigaku Geigerflex SG-7.

\section{RESULTS}

\section{X-ray Diffraction of CDA-Benzyl Alcohol Gel}

The X-ray diffraction patterns of CTA, CDA and CDA-benzyl alcohol gel are compared in Figure 1 and the $d$-spacings are summarized in Table II. We

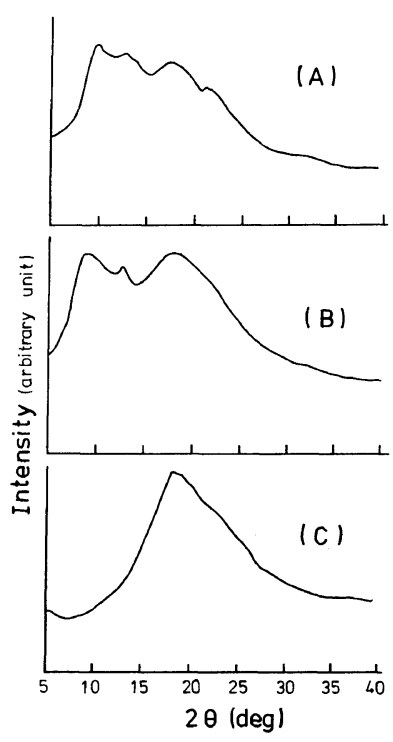

Figure 1. X-ray diffraction patterns of (A) a cellulose triacetate film, (B) a cellulose diacetate film, and (C) a film of cellulose diacetate-benzyl alcohol gel. 
Table II. Comparison of observed and calculated $d$ spacings of CTA, CDA, and the CDA gel

\begin{tabular}{ccccc}
\hline & & \multicolumn{3}{c}{ CTA FORM I } \\
\cline { 3 - 5 } & $2 \theta / \mathrm{deg}$ & $d_{\text {obs }} / \AA$ & $d / \AA$ & $(h k l)$ \\
\hline & & & & \\
\hline \multirow{2}{*}{ CDA } & $9.2(\mathrm{~s})$ & 9.60 & 9.56 & $\overline{1} 01$ \\
& $12.6(\mathrm{~m})$ & 7.02 & 7.07 & $\overline{1} 11$ \\
& $17.7(\mathrm{~s})$ & 5.01 & 5.07 & 012 \\
CTA & $9.9(\mathrm{~s})$ & 8.93 & 8.89 & 201 \\
& $12.9(\mathrm{~m})$ & 6.86 & 6.84 & 301 \\
& $17.6(\mathrm{~m})$ & 5.03 & 5.07 & 012 \\
& $21.6(\mathrm{~m})$ & 4.11 & 4.17 & 321 \\
Gel & $18.3(\mathrm{~s})$ & 4.84 & 4.78 & 202 \\
& & & & \\
\hline
\end{tabular}

did not attempt to promote the crystallization of CTA and CDA films by streching or rolling, since our purpose was only to compare the X-ray diffraction pattern of the gel with that of CTA and CDA films. Although the X-ray diffraction patterns of CTA and CDA films did not show high crystallinity, the patterns nevertheless indicate that the cellulose triacetate form I crystallites ${ }^{9}$ exist in the films. The Xray pattern of the gel also exhibited very low crystallinity, corresponding to the CTA-I form. Therefore, the existence of small crystallites which perform the role of crosslinking loci clearly shown.

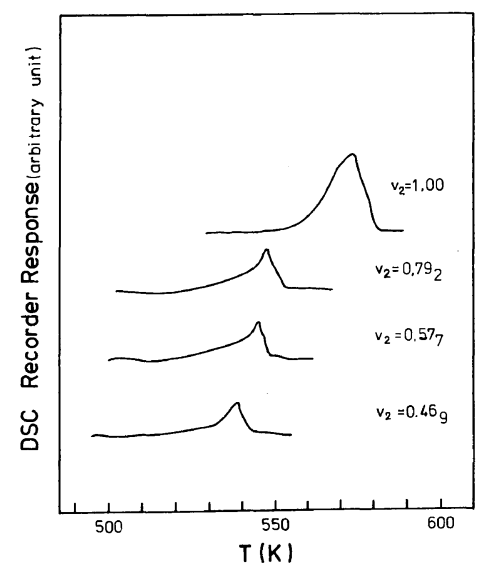

Figure 2. The DSC thermograms of cellulose triacetate-dibuthyl phthalate systems. The $v_{2}$ indicates the volume fraction of the CTA in the mixtures.

\section{Thermodynamic Properties}

Since the presence of the crystalline crosslinks of cellulose triacetate form I was established, we needed to measure the heat of fusion of CTA, since this has not been reported. The melting temperature of CTA was reported as $T_{\mathrm{m}}{ }^{0}=579 \mathrm{~K} .^{10}$ The CTA sample was mixed with dibutyl phthalate and the melting point depression of the CTA was measured. The DSC thermograms shown in Figure 2 definitely show that the melting point depression increases with an increasing volume fraction of the diluent.

It is also noticed that the area under each DSC peak becomes smaller and smaller with increasing of the volume fraction of diluent. According to Flory, ${ }^{11}$ the melting point depression of a polymer-diluent system is given by

$$
\frac{1 / T_{\mathrm{m}}-1 / T_{\mathrm{m}}^{0}}{v_{1}}=\frac{R}{\Delta h_{\mathrm{u}}} \frac{V_{\mathrm{u}}}{V_{1}}\left(1-\frac{B V_{1}}{R} \frac{v_{1}}{T_{\mathrm{m}}}\right)
$$

where $T_{\mathrm{m}}{ }^{0}$ is the melting temperature of the pure polymer, $\Delta h_{\mathrm{u}}$ is the heat of fusion per monomer unit, $v_{1}$ is the volume fraction of diluent, $V_{\mathrm{u}}$ and $V_{1}$ are the molar volumes of a monomer unit and diluent, respectively, and $B$ is the cohesive energy density. In Figure $3,\left(1 / T_{\mathrm{m}}-1 / T_{\mathrm{m}}{ }^{0}\right) / v_{1}$ in plotted against $v_{1} / T_{\mathrm{m}}$ and a straight line is obtained. From the plot, we obtain $\Delta h_{\mathrm{u}}=2360 \mathrm{cal} \mathrm{mol}^{-1} \quad\left(9.87 \mathrm{~kJ} \mathrm{~mol}^{-1}\right)$ and $B=5.4 \mathrm{cal} \mathrm{ml}^{-1}\left(22.59 \mathrm{~J} \mathrm{~cm}^{-3}\right)$. Since the observed melting temperature of cellulose triacetate was $576 \mathrm{~K}$ which is almost identical with the literature value $(579 \mathrm{~K})$, the entropy of the fusion per monomer unit, $\Delta S_{\mathrm{u}}, \quad$ is equal to $4.09 \mathrm{cal} \mathrm{mol}^{-1} \mathrm{deg}^{-1}$ $\left(17.11 \mathrm{~J} \mathrm{~mol}^{-1} \mathrm{deg}^{-1}\right)$. This value is about two thirds of the $\Delta S_{\mathrm{u}}$, of cellulose tributyrate. ${ }^{12}$

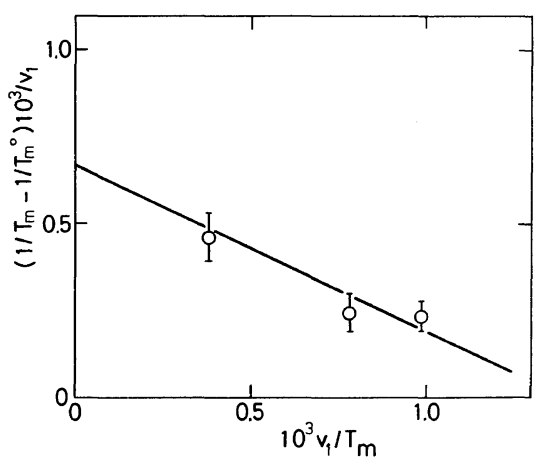

Figure 3. The $\left(1 / T_{\mathrm{m}}-1 / T_{\mathrm{m}}{ }^{0}\right) / v_{1}$ vs. $v_{1} / T_{\mathrm{m}}$ plot. 


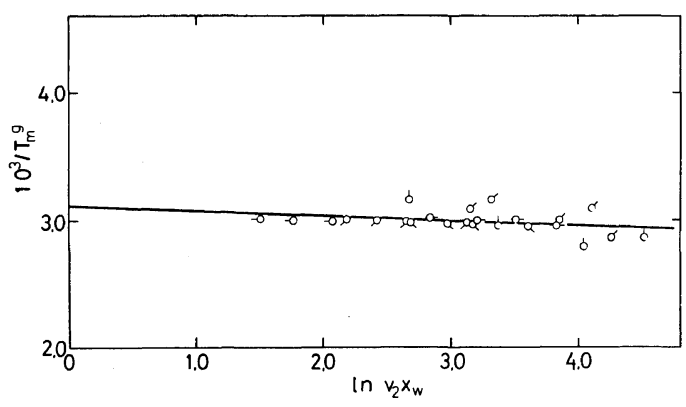

Figure 4. The reciprocals of the gel melting temperature vs. $\ln v_{2} x_{w}$ plots. Degrees of polymerization $x_{w}: \delta$, $1391 ; \bigcirc, 1165 ; \bigcirc-865 ; \mathrm{Q}, 559 ; \bigcirc, 416 ;-\bigcirc, 184$.

\section{Melting Temperature of Cellulose Acetate Gel}

In Figure 4, the reciprocals of the gel melting temperature of CDA-benzyl alcohol gels are plotted against $\ln v_{2} x_{w}$. The plot is linear and moreover almost independent of the molecular weight of CDA indicating that the Eldridge-Ferry like plot is applicable. This is understandable since the degree of substitution of the samples is almost the same in each case. The intercept of the plot is $3.08 \times 10^{-3} \mathrm{~K}^{-1}$ and the slope is $3.38 \times 10^{-5} \mathrm{~K}^{-1}$.

The interaction term $B^{\prime}$ was estimated by the relationship

$$
A_{2}=\frac{\bar{v}^{2}}{V_{1}}\left(\frac{1}{2}-\frac{B^{\prime} V_{1}}{R T}\right)
$$

where $A_{2}$ is the second virial coefficient, and $\bar{v}$ is the specific volume of CDA in solvent. Tanner and Berry ${ }^{8}$ reported that the value of $A_{2}$ of CDA is equal to $-2.013 \times 10^{-5} \mathrm{~mol} \mathrm{ml}^{-1} \mathrm{~g}^{-2}$ in benzyl alcohol. Using eq 4 , we obtain $B^{\prime}=3.167 \mathrm{cal} \mathrm{ml}^{-1}$ $\left(13.25 \mathrm{~J} \mathrm{~cm}^{-3}\right)$. Making use of $\Delta h_{\mathrm{u}}=2360 \mathrm{cal} \mathrm{mol}^{-1}$ $\left(9.87 \mathrm{~kJ} \mathrm{~mol}^{-1}\right) ; \quad T_{\mathrm{m}}^{0}=579 \mathrm{~K} ; \quad V_{1}=103.5 \mathrm{ml} \mathrm{mol}^{-1}$ and $V_{\mathrm{A}}=182.0 \mathrm{ml} \mathrm{mol}^{-1}$, and putting $X_{\mathrm{A}}=\mathrm{DS} / 3$, the crystalline sequence length $\zeta$ of triacetyl glucose units and the interfacial free energy $\sigma_{\mathrm{ec}}$ are estimated from the above values of the intercept and the slope

Table III. Experimental results and the estimation of $\zeta$ and $\sigma_{\mathrm{ec}}$

\begin{tabular}{cccc}
\hline $\begin{array}{c}\text { Intercept } \\
\times 10^{3} \mathrm{~K}^{-1}\end{array}$ & $\begin{array}{c}\text { Slope } \\
\times 10^{5} \mathrm{~K}^{-1}\end{array}$ & $\zeta$ & $\begin{array}{c}\sigma_{\mathrm{ec}} \times 10^{-3} \\
\text { cal mol }^{-1} \text { (of sequence) }\end{array}$ \\
\hline 3.08 & 3.38 & 18.5 & $2.9_{9}$ \\
\hline
\end{tabular}

a $1 \mathrm{cal} \mathrm{mol}^{-1}=4.184 \mathrm{~J} \mathrm{~mol}^{-1}$. by the procedure proposed previously. ${ }^{4}$ The results are shown in Table III and the length of the crystalline $\zeta$ is about 19 units and the interfacial free energy per crystalline sequence $\sigma_{\mathrm{ec}}$ is 2990 cal mol${ }^{-1}\left(12.51 \mathrm{~kJ} \mathrm{~mol}^{-1}\right)$ of sequence.

\section{DISCUSSION}

The X-ray diffraction pattern of the CDA gel showed the presence of the crystalline order of the cellulose triacetate form $I$ in the gel. The value of $\zeta$ indicates that small runs of triacetylglucose unit in CDA chains are responsible for this order. The occurrence of these triacetylglucose units is in consequence of the heterogeneous hydroysis reaction of the CTA. Since the $\zeta$ is 19 , the length of crystallite will then be $100 \AA$, since the crystallite is the cellulose triacetate form I. Although our theory could not give the number of crystalline sequences in a crystallite, judging from the $\mathrm{X}$-ray diffraction peak, there may be several such sequences.

From the X-ray small angle scattering of the cellulose diacetate-benzyl alcohol gel, Goeble and Berry ${ }^{3}$ estimated that the radius of gyration $\left\langle\mathbf{S}^{2}\right\rangle^{1 / 2}$ of the cross linking loci is $57 \AA$ and that the effective diameter $D=2 \cdot\left(5\left\langle\mathbf{S}^{2}\right\rangle / 3\right)^{1 / 2}$ is $147 \AA \cdot$ Although our estimation of the crystallite length is thermodynamic, the length of the crystallite $100 \AA$ compared favorably with the estimated sizes of the cross linking loci. The effective diameter is about 1.5 times larger than our estimation. However, the size of the cross linking loci estimated by X-ray small angle scattering is considered to include not only the crystallite but also the amorphous chain sequences which emerge from the ends of the crystallite. Thus, the loci are the fringed micelle, making possible a large effective diameter. Consequently, we may say that both estimations, the X-ray small angle scattering method and the thermodynamic approach, are in reasonable agreement.

In conclusion, the gel melting temperature of the cellulose diacetate-benzyl alcohol gel can be predicted by the theory and the length of the "cross linking loci" of the gel is about $100 \AA$.

Acknowledgment. We are indebted to Mr. Akira Fujikawa and Mr. Kenji Tsuda from Daicel Company, for their kind supply of samples. 


\section{REFERENCES}

1. E. W. J. Mardles, Trans. Faraday Soc., 18, 318, 327, 353, and 365 (1923); Kolloid Z., 49, 4 and 11 (1929).

2. S. A. Glikman, L. A. Roth, L. I. Khomutov, E. N. Gubenkova, and I. I. Reigelson, J. Polym. Sci., C, No. 16, 2001 (1967).

3. K. D. Goebel and G. C. Berry, J. Polym. Sci., Polym. Phys. Ed., 15, 555 (1977).

4. A. Takahashi, T. Nakamaura, and I. Kagawa, Polym. J., 3, 207 (1972).

5. A. Takahashi, Polym. J., 4, 379 (1973); A. Takahashi and S. Hiramitsu, ibid., 6, 103 (1974).

6. T. Kato, M. Yokoyama, and A. Takahashi., Colloid
Polym. Sci., 256, 15 (1978).

7. H. C. Haas and R. L. MacDonald, J. Polym. Sci., Polym. Rhys. Ed., 11, 1133 (1973).

8. D. W. Tanner and G. C. Berry, J. Polym. Sci., Polym. Phys. Ed., 12, 941 (1974).

9. B. S. Sprague, J. L. Riley, and H. D. Noether, Text. Res. J., 28, 275 (1958).

10. C. J. Malm, J. W. Mench, D. L. Kendall, and G. D. Hiatt, Ind. Eng. Chem., 43, 688 (1951).

11. P. J. Flory, "Principles of Polymer Chemistry," Cornell University Press, Ithaca, N. Y., 1953, p 513.

12. L. Mandelkern and P. J. Flory, J. Am. Chem., Soc., 73, 3026 (1951). 